Article

\title{
In Vitro Evaluation of a Peptide-Mesoporous Silica Nanoparticle Drug Release System against HIV-1
}

\author{
Katharina Braun ${ }^{1, \dagger}$, Christina M. Stürzel ${ }^{2, \dagger}$, Frank Kirchhoff ${ }^{2}$ and Mika Lindén ${ }^{1, *}$ \\ 1 Inorganic Chemistry II, Ulm University, Albert-Einstein-Allee 11, 89081 Ulm, Germany; \\ kathal.braun@googlemail.com \\ 2 Institute of Molecular Virology, Ulm University Medical Centre, Meyerhofstraße 1, 89081 Ulm, Germany; \\ christina.stuerzel@uni-ulm.de (C.M.S.); Frank.Kirchhoff@uni-ulm.de (F.K.) \\ * Correspondence: mlinden@uni-ulm.de \\ $\dagger$ Equal contribution.
}

Received: 4 May 2020; Accepted: 6 July 2020; Published: 13 July 2020

check for

\begin{abstract}
It has been shown that the optimized VIR-576 derivative of the natural HIV-1 entry inhibitor targeting the viral gp41 fusion peptide is safe and effective in infected individuals. However, high doses of this peptide were required, and stability, as well as delivery, must be improved for clinical application. Here, we examined the loading and release of VIR-576 into/from mesoporous silica nanoparticles (MSNs) in vitro. We found that a moderately high peptide loading of $11.5 \mathrm{wt} \%$ could be achieved by adsorption from PBS buffer ( $\mathrm{pH}$ 7.2), i.e., under mild, fully peptide-compatible conditions. The release rate of peptide into the same buffer was slow and the equilibrium concentration as indicated by the adsorption isotherm could not be reached even within $50 \mathrm{~h}$ at the particle concentrations studied. However, a faster release was observed at lower particle concentrations, indicating that partial particle dissolution had a positive influence on peptide release. To determine the antiviral activity of VIR-576-loaded MSNs, TZM-bl indicator cells were exposed to HIV-1 and the infection rates were followed as a function of time and VIR- 576 concentration. The inhibitory activity observed for VIR-576 released from the MSNs was virtually identical to that of free VIR-576 at the $48 \mathrm{~h}$ time point, indicating that (a) VIR-576 was released in an active form from the MSNs, and (b) the release rate in the presence of serum proteins was clearly higher than that observed under protein-free conditions. These observations are discussed based on competitive peptide/protein adsorption, as well as potential influences of serum proteins on the dissolution-reprecipitation of silica under conditions where the total silica concentration is above the saturation level for dissolved silica. Our results highlight the need for studying drug release kinetics in the presence of serum proteins, in order to allow for a better extrapolation of in vitro data to in vivo conditions. Furthermore, due to the high peptide loadings that can be achieved using MSNs as carriers, such a formulation appears promising for local release applications. For systemic administration, however, peptides with a higher potency would be needed, due to their high molar masses limiting the drug loading in terms of moles per gram carrier.
\end{abstract}

Keywords: mesoporous silica; drug release; peptide drug; HIV-1

\section{Introduction}

As the first isolation and commercialization of insulin, a 51 amino acid peptide in the early 1920s, an ever-increasing number of peptide-based drugs are being commercialized and in clinical testing. Peptide-protein interactions are key for many biological processes $[1,2]$ and, while antibodies exhibit a higher specificity, peptides can reach sites within proteins that are not accessible for the larger antibodies. Peptides are also much cheaper to produce as compared to antibodies, which represents another clear advantage in terms of commercialization. Peptides showing, e.g., antimicrobial [3,4], 
anticancer [4], and antiviral [5] activity, have been reported, supporting the broad potential for therapeutic peptides. However, depending on the structural characteristics of the peptide, the blood half-life can be as short as minutes or hours [6] and the renal clearance kinetics from the body can also be high due to their small size. In combination with a suboptimal biodistribution, this leads to the need for high peptide doses, which compromises the benefits related to peptide drugs even in the case of peptides that show a high potency. One means for overcoming at least some of these limitations is to use a carrier system for the peptide that would shield it against enzymatic degradation until release. Furthermore, the biodistribution pattern and clearance kinetics could be influenced, as these are rather controlled by the carrier than by the peptide itself. However, carriers that can carry high peptide loadings are needed in order to minimize concentration-dependent carrier toxicity issues. An especially attractive peptide carrier particle platform is mesoporous silica nanoparticles (MSNs). Their high surface area and pore volume together with tunable mesopore diameters allow for peptide loadings as high as $20 \mathrm{wt} \%$ depending on the peptide, and several studies have demonstrated the suitability for enzyme and protein immobilization into MSNs, as recently reviewed [7,8], and MSNs even show promise for oral administration of macromolecular drugs $[9,10]$. We have recently shown that MSNs with pore sizes just slightly larger than the diameter of the peptide can efficiently shield the peptide against enzymatic degradation as long as the peptide remains inside the pore system of the carrier, as demonstrated for the antimicrobial peptide LL-37 [11]. These results are in full agreement with results obtained using larger proteins, like the enhanced green fluorescence protein, where Pepsin A-driven protein degradation was observed if the pore dimensions were clearly larger than those of the protein, while little or no protein degradation was observed in cases where the mesopore size was just slightly larger than the protein, as the protein was unable to unfold under these conditions [12]. As is the case for other antimicrobial peptides, LL-37 carries a positive charge under normal biological conditions, therefore exhibiting cellular membrane-disruptive properties. The surface charge of silica is negative under normal biological $\mathrm{pH}$-neutral conditions, which makes the positively charged peptide adsorb relatively strongly to the silica through electrostatic interactions, but the pore size of the mesoporous silica here also plays an important role for the interaction. If the pore diameter is slightly larger than the diameter of the peptide, the peptide can interact with multiple sites on the silica surface in all directions, which increases the affinity of the peptide for the silica support. If the pore diameter is just some nanometers larger, the affinity of the cationic peptide for the silica surface is greatly decreased, highlighting the enthalpic rather than the entropic driving force for peptide adsorption in that case [13]. Using another antimicrobial peptide, NZX, a novel derivative of the fungal antimicrobial peptide plectasin, and which is more potent than LL-37, we could also show that mesoporous silica particles administered into the lung of mice were very efficient in treating tuberculosis [14]. Here, bacteria residing intracellularly also have to be reached, and as mesoporous silica nanoparticles are readily taken up by cells, the efficient therapy using this peptide-carrier system can be understood. However, other peptides are effective extracellularly, and in such cases, cellular uptake of the carriers could even be counterproductive. An example of such a peptide is VIR-576, which is a derivative of the endogenous virus inhibitory peptide (VIRIP), which is derived from $\alpha$-antitrypsin and prevents HIV-1 entry [15]. The amino acid-sequence of VIR-576 is $\mathrm{NH}_{2}$-LEAIPCSIPPEFLFGKPFVF-LEAIPCSIPPEFLFGKPFVF-COOH, and it has a molar mass of $4483 \mathrm{~g} / \mathrm{mol}$ and a $\mathrm{pI}$ value of 5.4, i.e., it is negatively charged under $\mathrm{pH}$-neutral conditions. VIR-576 was safe and effective in a phase I/II clinical trial [12], and HIV-1 resistance to VIR-576 and other VIRIP-based inhibitors has a high genetic barrier and severe fitness costs [16]. The mechanism of action of VIR-576 is different from other HIV-1 inhibitors in that it binds to the hydrophobic gp41 fusion peptide and, thus, hinders its incorporation into the cellular membrane. Due to its distinct mode of action, VIR-576 remains active against HIV-1 strains that are resistant against other antiretroviral drugs [11]. In serum-free media, VIR-576 has a low $\mathrm{IC}_{50}$ value of $10-50 \mathrm{nM}$ and is, thus, several orders of magnitude more potent than VIRIP itself. However, this peptide also suffers from the shortcomings discussed above, and high doses of up to $5 \mathrm{~g}$ of VIR-576 had to be administered by infusion in the 
human trial [17]. VIR-576 is a cyclic peptide with a cross-section of $2.8 \mathrm{~nm}$, meaning that MSNs with pore diameters in the range of 3-4 nm would be ideal as carriers for VIR-576. Therefore, in this study, we investigated the suitability for mesoporous silica nanoparticles to serve as carriers for this anionic peptide. All experiments were carried out in vitro, and the study was designed to allow determination of the amount of VIR-576 released in active form from the mesoporous silica carriers as a function of time, mimicking local, extracellular delivery of VIR-576.

\section{Results and Discussion}

Monodisperse, mesoporous silica nanoparticles, MSNs, having a mean particle diameter of $170 \mathrm{~nm}$, were synthesized according to literature procedures [18,19]. After calcination, the particles had a mesopore diameter of $3 \mathrm{~nm}$, a BET surface area of $1069 \mathrm{~m}^{2} / \mathrm{g}$, and a pore volume of $0.5 \mathrm{~cm}^{3} / \mathrm{g}\left(\mathrm{p} / \mathrm{p}_{0}<0.8\right)$. A representative SEM image of the particles is shown in Figure 1a, and the nitrogen sorption isotherm is shown in Figure $1 \mathrm{~b}$.
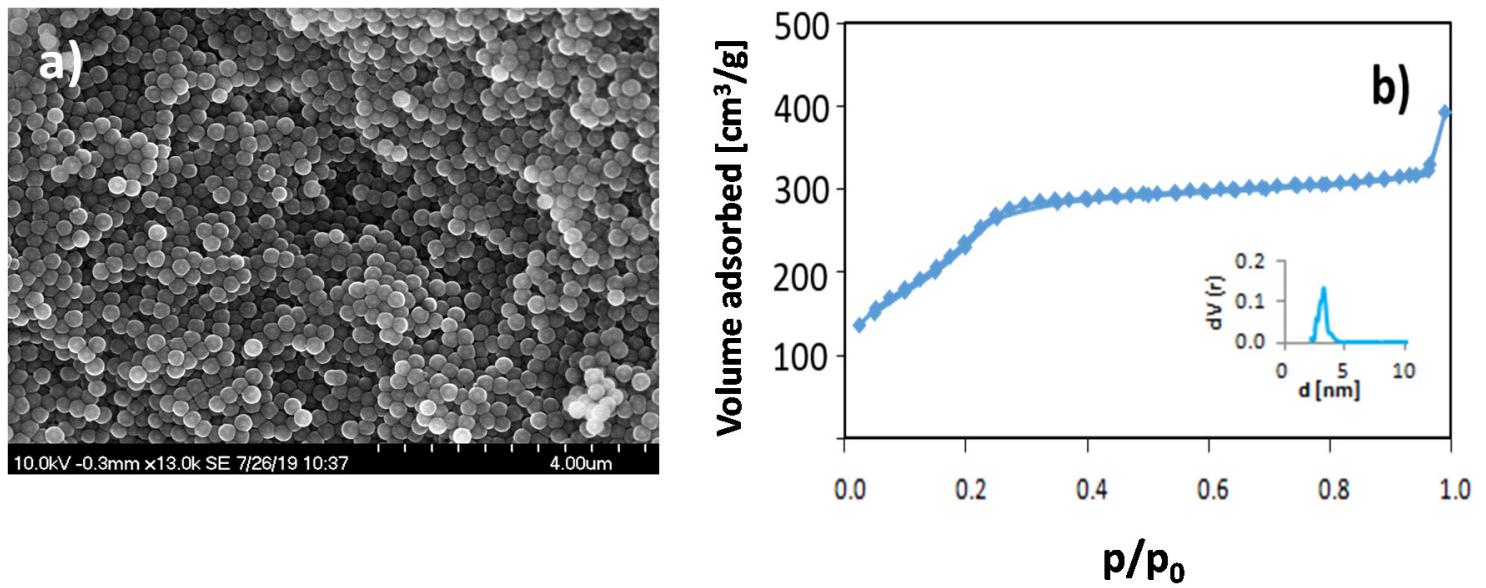

Figure 1. (a) SEM image of calcined mesoporous silica nanoparticles (MSNs) showing the narrow particle size distribution, and (b) the nitrogen sorption isotherm measured at $77 \mathrm{~K}$ for the same particles. The inset in Figure $1 \mathrm{~b}$ shows the pore size distribution plot.

VIR-576 was loaded into the MSN particles by adsorption from PBS buffer ( $\mathrm{pH}=7.2$ ), at room temperature for $1 \mathrm{~h}$, i.e., mild and fully peptide-compatible conditions, using a particle concentration of $5 \mathrm{mg} / \mathrm{mL}$. The relatively high particle concentration was chosen as it is well above the solubility limit of silica under the studied conditions (about 120-130 ppm), and, thus, particle dissolution effects could be minimized. The adsorption isotherm is shown in Figure 2.

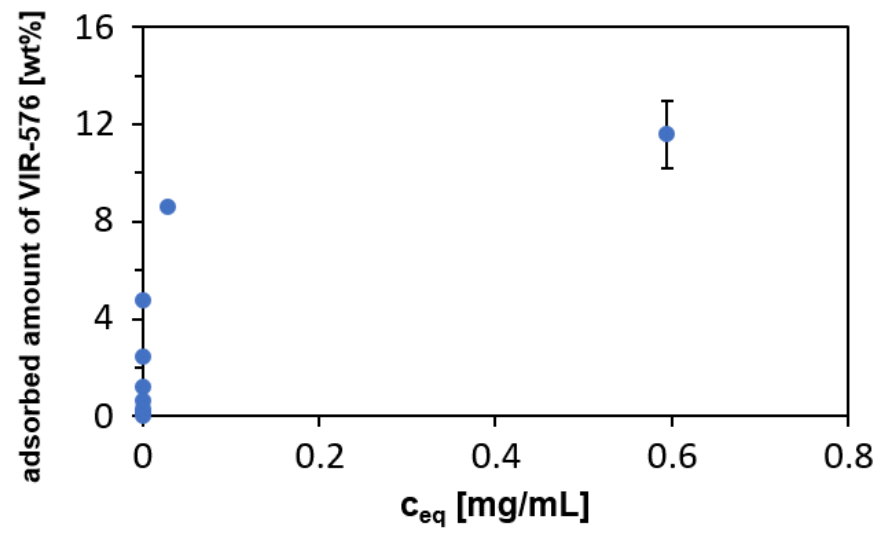

Figure 2. Adsorption isotherm of VIR-576 adsorbed onto MSNs from PBS $(\mathrm{pH}=7.2)$. Particle concentration: $5 \mathrm{mg} / \mathrm{mL}$, temperature $=25^{\circ} \mathrm{C}$, and incubation time $=1 \mathrm{~h}$. 
The adsorption follows Langmuir adsorption (linearized model, $\mathrm{R}^{2}=0.999, \mathrm{~K}=214.5 \mathrm{~mL} / \mathrm{mg}$, $\mathrm{b}=0.0858, \mathrm{q}_{\mathrm{m}}=11.65 \%$ ), suggesting a negligible contribution of peptide-peptide interactions. The steepness of the isotherm indicates a relatively strong interaction between the silica surface and VIR-576, although not as strong as observed previously for the cationic LL-37 peptide [11]. As the pI of VIR-576 is 5.40 and the isoelectric point, IEP, of silica is $2-3$, both the peptide and the silica are negatively charged under the studied conditions. The zeta potential as measured in PBS buffer ( $\mathrm{pH}=7.2$ ) was $-13 \mathrm{mV}$, in agreement with the negative surface charge of silica under the studied conditions. This highlights the importance of hydrogen-bonding and non-electrostatic forces for the adsorption. Furthermore, a pronounced entropic driving force for adsorption cannot be excluded, as the increase in entropy due to the release of surface water upon adsorption of macromolecules is a common driver for the adsorption of macromolecules to solid surfaces from aqueous solution.

The release of VIR-576 into PBS ( $\mathrm{pH}=7.2$ ) from MSNs having a VIR-576 loading degree of $11.5 \mathrm{wt} \%$ was studied as a function of time at room temperature using two different particle concentrations: 0.5 and $5 \mathrm{mg} / \mathrm{mL}$ MSNs. The results are shown in Figure 3.

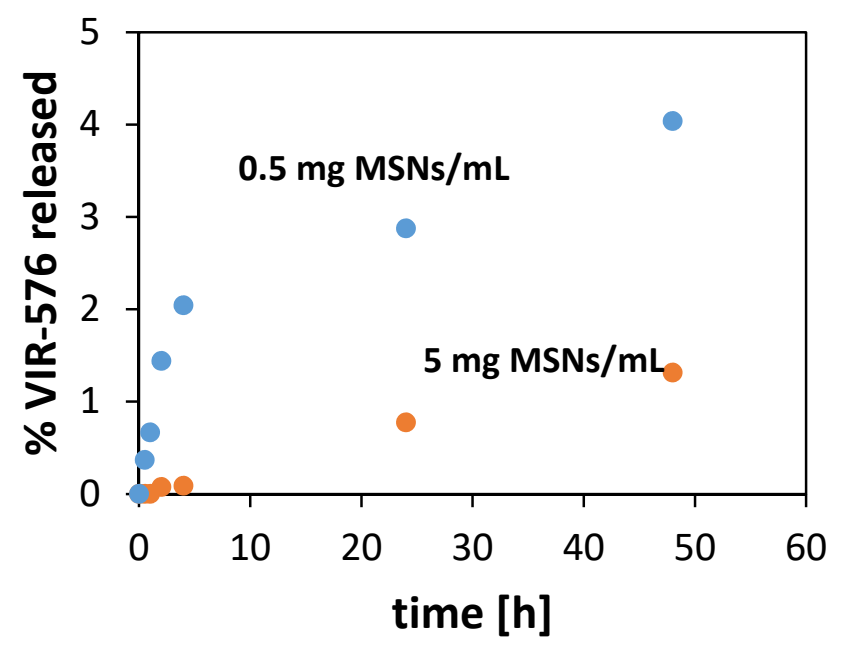

Figure 3. Release of VIR-576 into PBS buffer from MSNs having an initial VIR-576 loading of 11.5 wt \% as a function of particle concentration. $\mathrm{T}=25^{\circ} \mathrm{C}$. Error $= \pm 0.2 \%$-units.

As can be seen, the release of VIR-576 is slow but clearly depends on the particle concentration used in the experiments. Only about $1 \%$ of the adsorbed VIR-576 is released within $48 \mathrm{~h}$ at a particle concentration of $5 \mathrm{mg} / \mathrm{mL}$, while more than $4 \%$ of the peptide is released within the same time when a particle concentration of $0.5 \mathrm{mg} / \mathrm{mL}$ is used (Figure 3). In both cases, the released amount is lower than the equilibrium concentrations calculated based on the adsorption isotherm. The results indicate that particle dissolution has a pronounced influence on the release of VIR-576 from the MSNs, as a higher extent of particle dissolution is expected at the lower particle concentration [20]. Furthermore, it cannot be excluded that silica dissolution-reprecipitation effects, leading to a partial mesopore blocking, especially in the case of the higher particle concentration, contribute to the results, as the silica concentration exceeds the maximum solubility of silica under the applied conditions (about $130 \mathrm{ppm}$ at neutral $\mathrm{pH}$ and a temperature of $37^{\circ} \mathrm{C}$ ).

In order to shed some more light on the influence of particle dissolution kinetics on the VIR-576 release rate, and especially the influence of silica saturation on the dissolution and reprecipitation kinetics, particles were incubated in PBS $(\mathrm{pH}=7.2)$ at a concentration of $0.1 \mathrm{~g} / \mathrm{L}(100 \mathrm{ppm})$ and a temperature of $37^{\circ} \mathrm{C}$, i.e., below the saturation limit of amorphous silica, and at $5 \mathrm{~g} / \mathrm{L}$, i.e., well above the saturation limit of silica. At given time points, the concentration of silicon (Si) in the supernatant was determined by ICP-OES. The data are shown in Figure 4. 

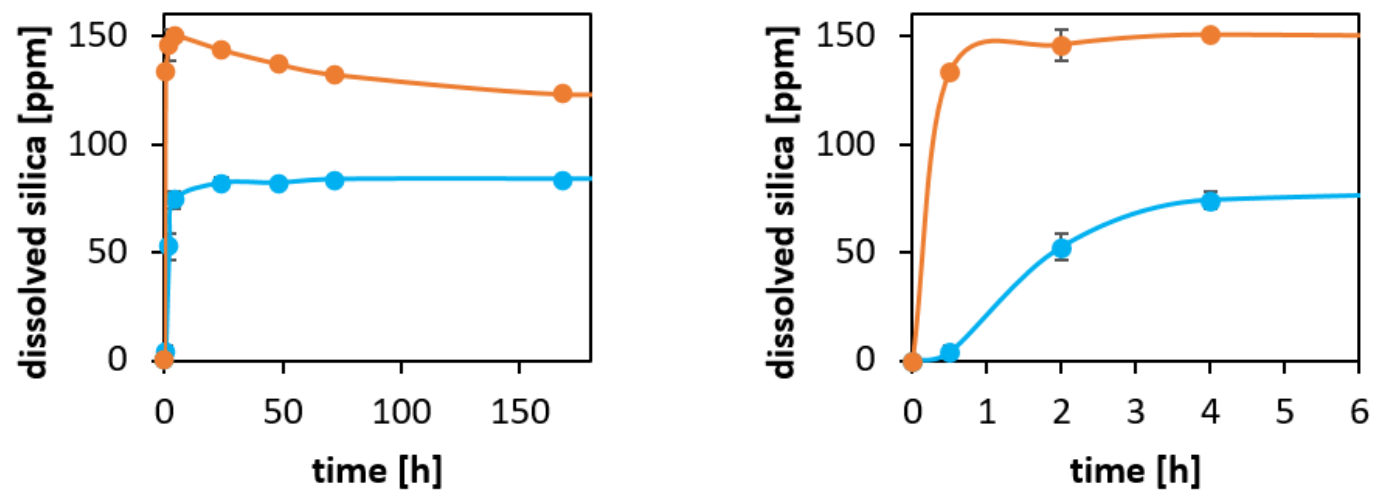

Figure 4. Left: Silicon concentrations measured by ICP-OES as a function of incubation time in PBS $(\mathrm{pH}=7.2)$ at $37^{\circ} \mathrm{C}$. Orange dots: $5 \mathrm{mg}$ particles $/ \mathrm{mL}$, blue dots: $0.1 \mathrm{mg}$ particles/mL. Right: Zoom highlighting the early stages of dissolution. The lines are guides for the eye.

For the higher particle concentration, a super-saturation level is reached within the first hours, and equilibrium was not reached within several days. Such a solution concentration behavior is typical for silica at high concentrations. For the lower concentration, a steady increase in the solution concentration until a steady concentration of about $80 \mathrm{ppm}$ was reached within the first $24 \mathrm{~h}$. This corresponds to a virtually complete dissolution of the particles. The reason for not reaching $100 \mathrm{ppm}$ is that the mesoporous silica particles are not in the form of fully condensed silica, $\mathrm{SiO}_{2}$, but contain an important fraction of $\mathrm{Q}^{3}$ and $\mathrm{Q}^{2}$ species, i.e., Si-centers that are not fully condensed. This is not considered in the calculation of the amount of dissolved silica based on the silicon concentration, for which a chemical composition of $\mathrm{SiO}_{2}$ was assumed. Thus, the silica dissolution curves give further support for the influence of silica dissolution and reprecipitation on the release kinetics of VIR-576 from the particles, discussed above.

In order to obtain information about the efficiency of the released VIR-576 in inhibiting HIV-1 infection, and about the concentrations of active VIR-576 released into 10\% FCS from VIR-576-loaded MSNs, we used an in vitro HIV-1 infection model using TZM-bl cells. This cell line is highly susceptible to HIV infection and contains integrated copies of the luciferase and B-galactosidase genes under control of the HIV-1 promoter, allowing convenient quantification of viral infection rates [21,22]. We first studied the concentration-dependent HIV infection inhibition of free VIR-576 as a function of pre-incubation time before adding the virus. The results are shown in Figure 5. A VIR-576 concentration of $6.2 \mu \mathrm{M}$ was sufficient to virtually completely inhibit the infection if the pre-incubation time did not exceed $4 \mathrm{~h}$. Effective inhibition of HIV infection was observed at a pre-incubation time of $24 \mathrm{~h}$, and which was even more evident at $48 \mathrm{~h}$, reflecting the serum instability of VIR- 576 .

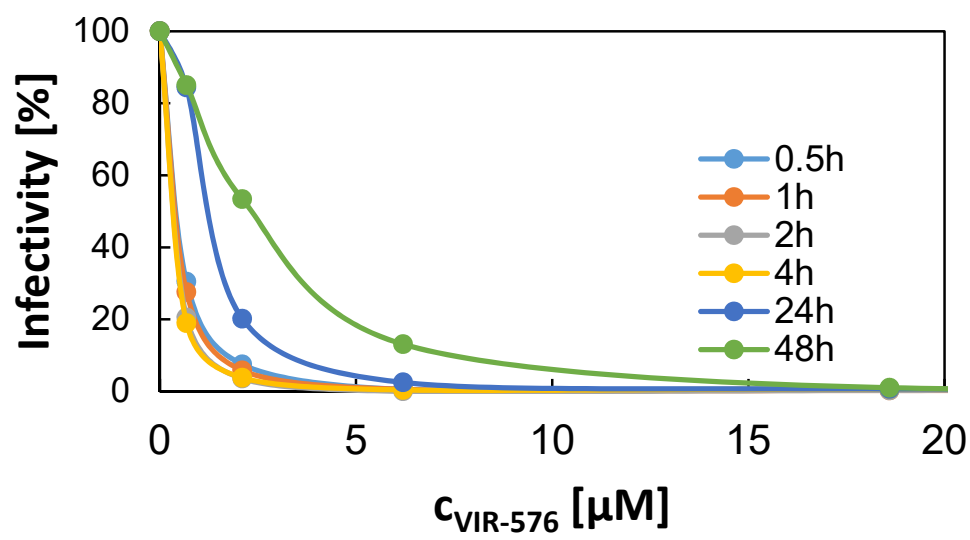

Figure 5. Concentration-dependent VIR-576-induced inhibition of HIV-1 infection in TZM-bl cells in vitro as a function of pre-incubation time in $10 \%$ fetal calf serum (FCS) before addition of the HIV-1 virus. Error smaller than the size of the data points. 
The results obtained as a function of pre-incubation time for the free VIR-576 peptide and for the released VIR-576 from the MSNs are summarized in Figure 6. In good agreement with the release of VIR-576 into PBS, very limited virus inhibition was observed after a release time of $4 \mathrm{~h}$. After a release time of $24 \mathrm{~h}$, the HIV infection inhibition by the released VIR-576 was clearly increased but still remained low. After a release time of $48 \mathrm{~h}$, the efficiencies of HIV-1 inhibition measured for the free peptide and for the released VIR-576 were very similar. This reflects the increased release of VIR-576 from the particles over time, as well as the decreased virus inhibition efficiency of the free peptide over time. Thus, the results indicate that the VIR-576 remains active after adsorption into and release from the MSNs. Data measured for empty MSNs are also included, showing that the particles themselves have little influence on the measured virus inhibition efficiencies. Furthermore, the cell viability was not affected by the presence of the MSNs under the studied conditions, and remained in the range of $100 \pm 10 \%$ during the time frame studied (data not shown) excluding cytotoxicity-related effects. These result show that the release rate of VIR-576 from the MSNs is clearly higher in the presence of serum proteins, as release rates as those measured in the absence of proteins (Figure 3) would by far not allow it to reach levels sufficient to achieve the observed effective inhibition of HIV-1 infection.
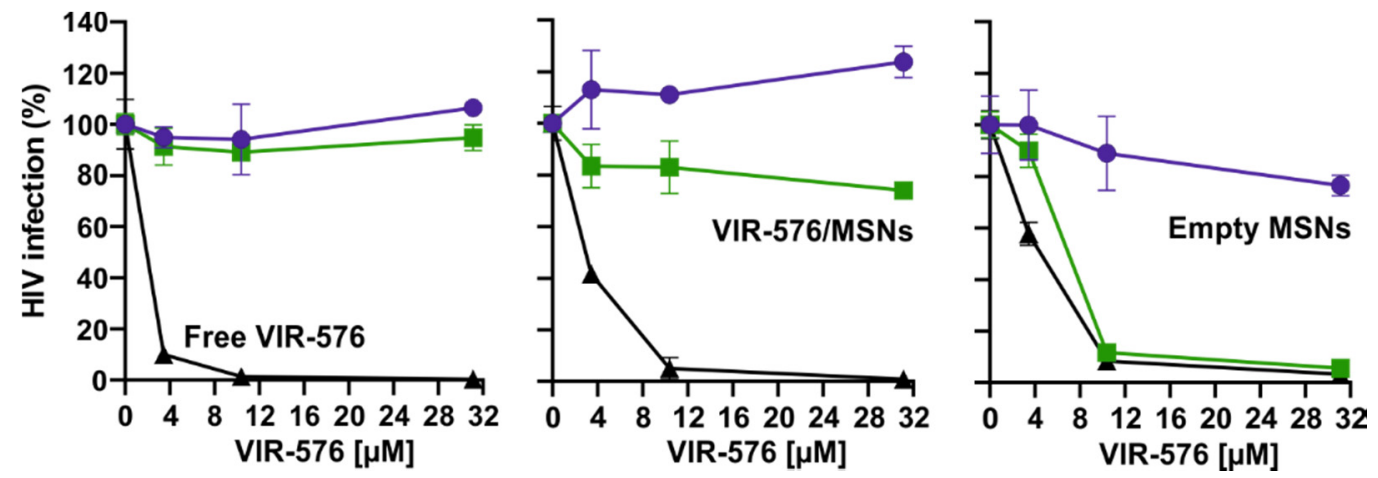

Figure 6. VIR-576-concentration-dependent HIV-1 NL4-3 infectivity inhibition as a function of pre-incubation time in 10\% FCS for free peptide, and peptide released from MSNs. Color coding as indicated in the figures. See experimental for details.

The dissolution rate of mesoporous silica nanoparticles has been shown to be reduced in the presence of serum proteins [23]. Thus, the observed faster release of VIR-576 from the MSNs in FCS cannot be ascribed to a faster MSN degradation, although a faster release of VIR-576 was observed under more dilute conditions where silica degradation is important under protein-free conditions, as discussed above. We, therefore, assign the faster VIR-576 release observed in the presence of serum proteins to the influence of competitive adsorption of proteins to the silica surface, replacing the pre-adsorbed peptide. Such an effect is mechanistically similar to the Vroman effect [24], where less strongly bound proteins are replaced by more strongly binding but slow-diffusing larger proteins over time, giving rise to a very dynamic equilibrium at surfaces in contact with protein-containing media [25,26]. The VIR-576-particle interaction being mainly of non-electrostatic nature can be overcome by more strongly adsorbing proteins present in the FCS, and particle restructuring effects present, even if a net-dissolution of silica would not take place, can also open up the pore system of the particles, providing further access of serum proteins to the inner mesopore system of the particles over time. This conclusion is further supported by studies using binary mixtures of proteins having different $\mathrm{pI}$ values, and where the protein adsorption could be tuned by changing the $\mathrm{pH}$ of the solution so that one or the other protein showed a favorable electrostatic interaction with the silica surface [27]. On this note, it cannot be excluded that the presence of adsorbed proteins on the particle surface also influences the re-precipitation of silica, potentially leading to pore-blocking in the absence of proteins, as discussed above. 


\section{Experimental}

\subsection{Chemicals}

Tetramethylorthosilicate (TMOS, purum, $\geq 98 \%$, Fluka Analytical (Altmann Analytik Gmbh \& Co. KG, München, Germany), cetyltrimethylammonium bromide (CTAB, $\geq 98 \%$, Sigma-Aldrich, St. Louis, MO, USA), (3-aminopropyl)trimethoxysilane (APTS, 97\%, Aldrich Chemistry, Merck KGaA, Darmstadt, Germany), methanol (MeOH, technical, VWR, Ulm, Germany), ethanol (EtOH, $99.5 \%$ denatured with $1 \%$ methyl ethyl ketone, VWR), sodium hydroxide $(\mathrm{NaOH}, \geq 98 \%$, Sigma Aldrich), carboxyethylsilanetriol sodium salt ( $25 \%$ in water, abcr GmbH, Karlsruhe, Germany), 4-(2-hydroxyethyl)-1-piperazineethanesulfonic acid (VWR), toluene (99\%, Sigma-Aldrich), Dulbecco's phosphate buffered saline (PBS, Life Technologies, Carlsbad, CA, USA), and Milli-Q water. All chemicals were used as received.

\subsection{Nanoparticle Synthesis and Characterization}

Mesoporous silica nanoparticles (MSN) were synthesized according to the procedure used by Rosenholm et al. [18] and which is a modification based on the synthesis described by Nakamura et al. [19]. In a typical synthesis, $1.19 \mathrm{~g}$ of tetramethoxysilane (TMOS) was mixed with APTS under inert atmosphere and added to an alkaline solution containing the structure-directing agent cetyltrimethyl ammonium chloride (CTAB). The resulting synthesis mixture had a molar ratio of 0.9 TMOS:0.1 APS:1.27 CTAB:0.26 NaOH:1439 MeOH:2560 $\mathrm{H}_{2} \mathrm{O}$. The sol was stirred overnight at room temperature $\left(25^{\circ} \mathrm{C}\right)$, and thereafter aged for $8 \mathrm{~h}$ in static conditions. The precipitate was filtered off, washed with deionized water, and dried at $45^{\circ} \mathrm{C}$ in vacuo for $72 \mathrm{~h}$. The structure-directing agent was subsequently removed by ultrasonication in acidic $(\mathrm{HCl})$ ethanol (about $0.12 w / w)$ three times. Particle size and morphology were characterized via scanning electron microscopy using a Hitachi S-5200 scanning electron microscope (SEM) (Hitachi, Tokyo, Japan) operated at $20 \mathrm{kV}$. Nitrogen sorption isotherms were measured at $-196^{\circ} \mathrm{C}$ using a Quadrasorb-SI (Quantachrome Instruments, Boynton Beach, FL, USA), and the pore size distributions were calculated using an non-local density functional theory (NLDFT) equilibrium kernel developed for silica (Quantachrome). Samples were outgassed at $140^{\circ} \mathrm{C}$ for a minimum of $8 \mathrm{~h}$ prior to measurements. The zeta potential was determined in $10^{-3} \mathrm{M} \mathrm{KCl}$ using a Malvern Zetasizer Nano ZS (Malvern Panalytical, Malvern, UK) at a particle concentration of $100 \mu \mathrm{g} / \mathrm{mL}$.

Biodegradability was studied via dissolution experiments in PBS and DMEM3+ at $37{ }^{\circ} \mathrm{C}$ and a particle concentration of $0.1 \mathrm{~g} / \mathrm{L}$. After given time points, samples were taken from the test tube and particles were separated from the supernatant. The silicon concentration in the supernatant was measured by an inductively coupled plasma optical emission spectrometer (ICP-OES), an Ultima 2 inductively coupled plasma optical emission spectrometer (ICP-OES) from Horiba Jobin Yvon S.A.S. (Longjumeau, France).

\subsection{Peptide Adsorption on MSN}

Loading of VIR-576 was performed by incubating a dispersion of mesoporous silica nanoparticles (particle concentration $5 \mathrm{mg} / \mathrm{mL}$ ) with $1 \mathrm{mM}$ solution of VIR-576 in PBS $(\mathrm{pH}=7.2)$. After an incubation time of one hour, the particles were separated from the solution by centrifugation and the peptide concentration was measured indirectly in the supernatant by virus inhibition tests.

Nitrogen sorption isotherms of peptide-loaded particles were measured at $-196{ }^{\circ} \mathrm{C}$ using a Quadrasorb-SI (Quantachrome Instruments, Boynton Beach, FL, USA), and the pore size distributions were calculated using an NLDFT equilibrium kernel developed for silica (Quantachrome). Samples were outgassed at $25{ }^{\circ} \mathrm{C}$ for a minimum of $8 \mathrm{~h}$ prior to measurements. ATR-FTIR spectra of loaded and non-loaded mesoporous silica nanoparticles were recorded with a spectral resolution of $2 \mathrm{~cm}^{-1}$ using a Bruker Tensor 27 spectrometer equipped with a diamond crystal as the ATR element (PIKE Miracle ${ }^{\mathrm{TM}}$, PIKE Technologies, Madison, WI, USA). 


\subsection{Peptide Release from MSNs in the Absence of Cells}

Peptide-loaded particles were prepared by incubating particles $(5 \mathrm{mg} / \mathrm{mL})$ with a peptide solution $(1 \mathrm{mg} / \mathrm{mL})$ in PBS, resulting in a peptide loading of $12.5 \mathrm{wt} \%$. After one hour of adsorption, the loaded particles were separated from the solution by centrifugation and washed twice with PBS. Loading was measured by determining the peptide concentration in the supernatant and washing solutions through virus inhibition tests. After the loading procedure, the particles were redispersed (particle concentrations of 5 and $0.5 \mathrm{mg} / \mathrm{mL}$ ) in the corresponding release media, either PBS or DMEM3+, and incubated at $37^{\circ} \mathrm{C}$. After $0.5,1,2,4,6,24,48,72$, and $168 \mathrm{~h}$, samples of $2 \mathrm{~mL}$ were isolated, particles were separated, and concentrations of active peptide were determined indirectly by HIV-1 virus inhibition tests.

\subsection{Cell Culture}

The TZM-bl cell line was obtained through the NIH ARRRP and cultured in cell culture medium DMEM 3+ (DMEM medium supplemented with $120 \mu \mathrm{g} / \mathrm{mL}$ penicillin, $120 \mu \mathrm{g} / \mathrm{mL}$ streptomycin, $350 \mu \mathrm{g} / \mathrm{mL}$ glutamine, and 10\% heat-inactivated fetal calf serum (FCS), Gibco, Life Technologies, Frederick, MD, USA) in an atmosphere of $5 \% \mathrm{CO}_{2}$ at $37^{\circ} \mathrm{C}$. TZM-bl cells are derived from human cervical carcinoma cells (HeLa) stably transfected with CD4 and CCR5 and expressing endogenous levels of CXCR4. Luciferase and $\beta$-galactosidase genes are encoded under control of the HIV LTR-promoter [20].

\subsection{HIV-1 Infection Assay}

First, 10,000 TZM-bl cells were seeded in 96-well plates. The next day, MSN, loaded MSN, or peptides were added in serial dilutions to the cells. After incubation times between 0.5 and $72 \mathrm{~h}$, cells were infected with HIV-1 NL4-3. Three days later, the infection of the cells was determined using a $\beta$-galactosidase assay. As luciferase and $\beta$-galactosidase genes are encoded under control of the HIV LTR-promoter, the expression of the HIV regulatory protein Tat triggers transcription of the lacZ gene under the control of the LTR promoter. The Tat-mediated, active lac $Z$ gene transcription leads to $\beta$-galactosidase production, and cleavage of a provided substrate by $\beta$-galactosidase results in a luminescent product that can be detected by a luminometer.

\subsection{CellTiter-Glo ${ }^{\circledR}$ Luminescent Cell Viability Assay}

After a 3 day treatment of TZM-bl cells in 96-well plates, the media were removed, and $50 \mu \mathrm{L}$ PBS and $50 \mu \mathrm{L}$ CellTiterGlo solution were added. After $2 \mathrm{~min}$ of shaking and $10 \mathrm{~min}$ of incubation time, cell viability was measured with a luminometer. As a background control, three wells with $100 \mu \mathrm{L}$ of cell culture medium were included. Fold-number of living cells could be determined by comparing these results to the levels of untreated control.

\section{Summary and Outlook}

Our results highlight the need for studying the release of bioactives from carrier particles under conditions more closely mimicking the in vivo situation, especially taking the influence of serum proteins on the release kinetics into account. In vitro release studies are often carried out in the absence of serum proteins for analytical reasons, but the use of an assay providing a quantitative, biological readout is an attractive alternative to lengthy and complicated quantitative peptidomics and proteomics analyses, where the peptide/protein concentration in the complex biofluid is determined. In terms of the specific therapeutic implications of the present study, it is shown that the peptide is not released from the particles at time-scales less than $24 \mathrm{~h}$, which corresponds to the relevant time-scale within which long-circulating MSNs can passively accumulate to larger degrees in target organs or tumors, as recently reviewed [28]. It is also shown that both particle dissolution in combination with competing protein adsorption enhance the rate of peptide release. Variations in the silica condensation 
degree [23], as well as in the surface chemistry of the particles in order to modulate peptide and serum protein interactions with the MSNs, represent promising future possibilities for optimization of the kinetics of peptide release from the MSNs. Such optimized VIR-576-loaded MSNs will be examined, e.g., in humanized mouse models to further assess their potential for the therapy of HIV/AIDS.

Author Contributions: K.B. synthesized and characterized the MSNs, carried out the peptide loading and release studies in buffer, and performed the dissolution study. She also analyzed this data. C.M.S. carried out all in vitro measurements involving cells, and analyzed the data. F.K. supervised the cell work and contributed to writing the manuscript. M.L. supervised the MSN-related work and carried the main responsibility for the writing of the manuscript. All authors have read and agreed to the published version of the manuscript.

Funding: This work was funded by the DFG-project CRC 1279 "Exploiting the human peptidome for novel antimicrobial and anticancer agents" (C.S., M.L., F.K.), and partly by the European Union's Seventh Framework Programme (FP7/2007-2013) under grant agreement no 604182, FORMAMP-Innovative Nanoformulation of Antimicrobial Peptides to Treat Bacterial Infectious Diseases (K.B., M.L.).

Conflicts of Interest: The authors declare no conflict of interest.

\section{References}

1. Midic, U.; Oldfield, C.J.; Dunker, A.K.; Obradovic, Z.; Uversky, V.N. Protein disorder in the human diseasome: Unfoldomics of human genetic diseases. BMC Genom. 2009, 10, S12. [CrossRef] [PubMed]

2. Tu, W.B.; Helander, S.; Pilstål, R.; Hickman, K.A.; Lourenco, C.; Jurisica, I.; Raught, B.; Wallner, B.; Sunnerhagen, M.; Penn, L.Z. Myc and its interactors take shape. Biochim. Biophys. Acta 2015, 1849, 469-483. [CrossRef] [PubMed]

3. Lei, J.; Sun, L.; Huang, S.; Zhu, C.; Li, P.; He, J.; Mackey, V.; Coy, D.H.; He, Q. The antimicrobial peptides and their potential clinical applications. Am. J. Transl. Res. 2019, 11, 3919-3931. [PubMed]

4. Gaspar, D.; Veiga, A.S.; Castanho, M.A.R.B. From antimicrobial to anticancer peptides. A review. Front. Microbiol. 2013, 4, 294. [CrossRef] [PubMed]

5. Gordon, Y.J.; Romanowski, E.G.; McDermott, A.M. A Review of Antimicrobial Peptides and Their Therapeutic Potential as Anti-Infective Drugs. Curr. Eye Res. 2005, 30, 505-515. [CrossRef] [PubMed]

6. Mathur, D.; Prakash, S.; Anand, P.; Kaur, H.; Agrawal, P.; Mehta, A.; Kumar, R.; Singh, S.; Raghava, G.P.S. PEPlife: A Repository of the Half-life of Peptides. Sci. Rep. 2016, 6, 36617. [PubMed]

7. Xu, C.; Lei, C.; Yu, C. Mesoporous Silica Nanoparticles for Protein Protection and Delivery. Front. Chem. 2019, 7, 290. [CrossRef]

8. Zhou, Z.; Hartmann, M. Progress in enzyme immobilization in ordered mesoporous materials and related applications. Chem. Soc. Rev. 2013, 42, 3894-3912. [CrossRef]

9. Abeer, M.M.; Meka, A.K.; Pujara, N.; Kumeria, T.; Strounina, E.; Nunes, R.; Costa, A.; Sarmento, B.; Hasnain, S.Z.; Ross, B.P.; et al. Rationally Designed Dendritic Silica Nanoparticles for Oral Delivery of Exenatide. Pharmaceutics 2019, 11, 418. [CrossRef]

10. Lamson, N.G.; Berger, A.; Fein, K.C.; Whitehead, K.A. Anionic nanoparticles enable the oral delivery of proteins by enhancing intestinal permeability. Nat. Biomed. Eng. 2020, 4, 84-96. [CrossRef]

11. Braun, K.; Pochert, A.; Lindén, M.; Davoudi, M.; Schmidtchen, A.; Nordström, R.; Malmsten, M. Membrane interactions of mesoporous silica nanoparticles as carriers of antimicrobial peptides. J. Colloid Interface Sci. 2016, 475, 161-170. [CrossRef] [PubMed]

12. Schlipf, D.M.; Rankin, S.E.; Knutson, B.L. Pore-Size Dependent Protein Adsorption and Protection from Proteolytic Hydrolysis in Tailored Mesoporous Silica Particles. ACS Appl. Mater. Interfaces 2013, 5, 10111-10117. [CrossRef] [PubMed]

13. Braun, K.; Pochert, A.; Gerber, M.; Raber, H.F.; Lindén, M. Influence of mesopore size and peptide aggregation on the adsorption and release of a model antimicrobial peptide onto/from mesoporous silica nanoparticles in vitro. Mol. Syst. Des. Eng. 2017, 2, 393. [CrossRef]

14. Tenland, E.; Pochert, A.; Krishnan, N.; Umashankar, R.K.; Kalsum, S.; Braun, K.; Glegola-Madejska, I.; Lerm, M.; Robertson, B.D.; Lindén, M.; et al. Effective delivery of the anti-mycobacterial peptide NZX in mesoporous silica nanoparticles. PLoS ONE 2019, 14, e0212858. [CrossRef] 
15. Münch, J.; Ständker, L.; Adermann, K.; Schulz, A.; Schindler, M.; Chinnadurai, R.; Pöhlmann, S.; Chaipan, C.; Biet, T.; Peters, T.; et al. Discovery and Optimization of a Natural HIV-1 Entry Inhibitor Targeting the gp41 Fusion Peptide. Cell 2007, 129, 263-275. [CrossRef]

16. Müller, J.A.; Glöckle, A.; Gawanbacht, A.; Geyer, M.; Münch, J.; Kirchhoff, F. Reduced Susceptibility to VIRIP-Based HIV-1 Entry Inhibitors Has a High Genetic Barrier and Severe Fitness Costs. J. Virol. 2018, 92, e00733-18. [CrossRef]

17. Forssmann, W.-G.; The, Y.-H.; Stoll, M.; Adermann, K.; Albrecht, U.; Barlos, K.; Busmann, A.; Canales-Mayordomo, A.; Giménez-Gallego, G.; Hirsch, J.; et al. Short-Term Monotherapy in HIV-Infected Patients with a Virus Entry Inhibitor Against the gp41 Fusion Peptide. Sci. Transl. Med. 2010, 2, 63 re3. [CrossRef]

18. Rosenholm, J.M.; Meinander, A.; Peuhu, E.; Niemi, R.; Eriksson, J.E.; Sahlgren, C.; Lindén, M. Targeting of Porous Hybrid Silica Nanoparticles to Cancer Cells. ACS Nano 2009, 3, 197-206. [CrossRef]

19. Nakamura, T.; Yamada, Y.; Yano, K. Direct Synthesis of Monodispersed Thiol-Functionalized Nanoporous Silica Spheres and Their Application to a Colloidal Crystal Embedded with Gold Nanoparticles. J. Mater. Chem. 2007, 17, 3726-3732. [CrossRef]

20. Wei, X.; Decker, J.M.; Liu, H.; Zhang, Z.; Arani, R.B.; Kilby, J.M.; Saag, M.S.; Wu, X.; Shaw, G.M.; Kappes, J.C. Emergence of Resistant Human Immunodeficiency Virus Type 1 in Patients Receiving Fusion Inhibitor (T-20) Monotherapy. Antimicrob. Agents Chemother. 2002, 46, 1896-1905. [CrossRef]

21. Braun, K.; Pochert, A.; Beck, M.; Fiedler, R.; Gruber, J.; Lindén, M. Dissolution kinetics of mesoporous silica nanoparticles in different simulated body fluids. J. Sol-Gel Sci. Technol. 2016, 79, 319-327. [CrossRef]

22. Platt, E.J.; Wehrly, K.; Kuhmann, S.E.; Chesebro, B.; Kabat, D. Effects of CCR5 and CD4 cell surface concentrations on infections by macrophagetropic isolates of human immunodeficiency virus type 1. J. Virol. 1998, 72, 2855-2864. [CrossRef] [PubMed]

23. Möller, K.; Bein, T. Degradable Drug Carriers: Vanishing Mesoporous Silica Nanoparticles. Chem. Mater. 2019, 31, 4364-4378. [CrossRef]

24. Vroman, L. Effect of Adsorbed Proteins on the Wettability of Hydrophilic and Hydrophobic Solids. Nature 1962, 196, 476-477. [CrossRef] [PubMed]

25. Malmsten, M. Ellipsometry and tirf studies of adsorption processes in parenteral drug delivery. Interface Sci. 1997, 5, 159-167. [CrossRef]

26. Green, R.J.; Davies, M.C.; Roberts, C.J.; Tendler, S.J.B. Competitive protein adsorption as observed by surface plasmon resonance. Biomaterials 1999, 20, 385-391. [CrossRef]

27. Moerz, S.T.; Huber, P. pH-Dependent Selective Protein Adsorption into Mesoporous Silica. J. Phys. Chem. C 2015, 119, 27072-27079. [CrossRef]

28. Lindén, M. Biodistribution and excretion of intravenously injected mesoporous silica nanoparticles: Implications for drug delivery efficiency and safety. Enzymes 2018, 43, 155-180. 